Int. J. Electrochem. Sci., 14 (2019) $2574-2588$

\title{
Sacrificial Template Synthesis of Copper Tungstate: Influence of Preparing Conditions on Morphology and Photoactivity
}

\author{
Ben Peng ${ }^{1}$, Chao Li ${ }^{2}$, Changsheng Yue ${ }^{1}$ and Peng Diao ${ }^{2, *}$ \\ ${ }^{1}$ Central Research Institute of Building and Construction Co. LTD., Energy Convention and \\ Environment Protection Co. LTD., State Key Laboratory of Iron \& Steel industry Environmental \\ Protection, Beijing 100088, China. \\ ${ }^{2}$ Key Laboratory of Aerospace Materials and Performance (Ministry of Education), School of \\ Materials Science and Engineering, Beihang University, Beijing 100191, China. \\ "E-mail: pdiao@buaa.edu.cn
}

doi: $10.20964 / 2019.03 .68$

Received: 14 October 2018 / Accepted: 10 December 2018 / Published: 7 February 2019

\begin{abstract}
Morphology-controlled synthesis of ternary transition metal oxides is very important for their application in many fields. As a typical n-type semiconductor ternary oxide, $\mathrm{CuWO}_{4}$ finds application in solar water splitting as a photoanode material. In this work, we successfully prepared the $\mathrm{CuWO}_{4}$ nanoflakes (NFs), nanoneedles (NNs) and nanoparticles (NPs) films via a thermal solid-state reaction using different $\mathrm{WO}_{3}$ as sacrificial templates. We systematically investigated the effect of the morphology, size, and crystal type of the $\mathrm{WO}_{3}$ templates on the resulting $\mathrm{CuWO}_{4}$. We found that the morphology and size of $\mathrm{WO}_{3}$ templates and the reaction temperature were crucial factors that dominated the formation and morphology of $\mathrm{CuWO}_{4}$. The well-crystallized $\mathrm{CuWO}_{4} \mathrm{NFs}_{\text {and }} \mathrm{NPs}$ were obtained at $550{ }^{\circ} \mathrm{C}$, whereas, the crystalline $\mathrm{CuWO}_{4} \mathrm{NNs}$ could be obtained at a much lower temperature of $475{ }^{\circ} \mathrm{C}$. All the obtained $\mathrm{CuWO}_{4}$ samples exhibited activity and good stability for photoelectrochemical (PEC) water oxidation. Among the $\mathrm{CuWO}_{4}$ samples, the NFs exhibited the highest activity, which was attributed to (1) the high light absorption efficiency obtained from the perpendicularly oriented NF structure and (2) the large electron density. This work reveals the dependence of morphology, crystallinity, and photoactivity of $\mathrm{CuWO}_{4}$ on the preparation conditions during sacrificial template synthesis.
\end{abstract}

Keywords: Copper tungstate; Sacrificial template synthesis; Photoelectrochemical water splitting.

\section{$\underline{\text { FULL TEXT }}$}

(C) 2019 The Authors. Published by ESG (www.electrochemsci.org). This article is an open access article distributed under the terms and conditions of the Creative Commons Attribution license (http://creativecommons.org/licenses/by/4.0/). 